\title{
Thermal behaviour of layered $\alpha$-titanium phosphates: From the titanium(IV) bis(hydrogenphosphate) monohydrate to an europium(III)-phase via propylamine intercalation
}

Jorge García-Glez ${ }^{1} \cdot$ Olena Khainakova $^{1} \cdot$ Isabel Iglesias $^{2} \cdot$ Belén F. Alfonso $^{2} \cdot$ José A. Huidobro $^{3} \cdot$ Zakariae $^{2}$ Amghouz $^{4} \cdot$ Aránzazu Espina $^{5} \cdot$ Camino Trobajo ${ }^{1}$

${ }^{I}$ Departamento de Química Orgánica e Inorgánica, Universidad de Oviedo-CINN, 33006 Oviedo, Spain. Departamentos de ${ }^{2}$ Física, ${ }^{3}$ Matemáticas, $y^{4}$ Ciencia de los Materiales e Ingeniería Metalúrgica, Escuela Politécnica de Ingeniería, Universidad de Oviedo, 33204 Gijón, Spain.

${ }^{5}$ Servicios Científico-Técnicos, Universidad de Oviedo, 33006 Oviedo, Spain.

(Zakariae Amghouz)amghouz.uo@uniovi.es

\begin{abstract}
Polycrystalline layered $\alpha$-titanum phosphate, $\alpha$-Ti( $\left(\mathrm{HPO}_{4}\right)_{2} \cdot \mathrm{H}_{2} \mathrm{O}$, has been obtained under $\mathrm{H}_{3} \mathrm{PO}_{4}(\mathrm{aq})$ reflux conditions, and its intercalation compound with propylamine, $\alpha-\mathrm{Ti}\left(\mathrm{HPO}_{4}\right)_{2} \cdot 2 \mathrm{C}_{3} \mathrm{H}_{7} \mathrm{NH}_{2} \cdot \mathrm{H}_{2} \mathrm{O}$, was used for trapping luminescent Eu-centers in two-dimensional confined space. All materials were characterized by X-ray powder diffraction (XPD), scanning electron microscopy (SEM), solid-state nuclear magnetic resonance (SS-NMR, ${ }^{31} \mathrm{P}$ MAS and ${ }^{13} \mathrm{C}$ CPMAS) and thermogravimetric analysis coupled with mass spectrometry (TG-MS). Moreover, the activation energy of thermal decomposition has been calculated as a function of the extent of conversion, applying both a modified Friedman method developed in our Lab and the advanced nonlinear method proposed by Vyazovkin.
\end{abstract}

Keywords: Titanium phosphate $\cdot$ Propylamine $\cdot$ Europium $\cdot$ Thermal decomposition $\cdot$ Kinetic analysis 


\section{Introduction}

$\alpha-\mathrm{Ti}\left(\mathrm{HPO}_{4}\right)_{2} \cdot \mathrm{H}_{2} \mathrm{O}(\alpha-\mathrm{TiP})$ was the subject of continuous study over the past fifty years. The pioneering studies on this material were conducted by Alberti in his Lab at the University of Perugia (Italy) [1,2] and emerged in the wake of the work of the Clearfield Lab (USA) on zirconium phosphates [3]. The contributions of the Soviet school, particularly the Chernukov Lab in Nizhni Nóvgorod (Russia) have also to be mentioned [4]. In this context, our group at the University of Oviedo (Spain), published its first articles on this topic at the beginning of the 1980s [5-7].

According to the excellent review of Clearfield and Díaz [8], the first report of a crystalline form of zirconium phosphate was in 1964. Up to that time, only an amorphous white fine powder was known. The transformation from the amorphous to crystalline form is a slow process. It is therefore possible to control the size of the particles from very small, approximately $50 \mathrm{~nm}$, up to micro-size and even to large crystals. These particles are layered and exhibit the ability to exchange positively charged species for protons, to undergo intercalation behaviour and exfoliation of the layers. In addition, it has been shown that the surface of the particles may be functionalized by bonding to silanes, isocyanates and epoxides, and this bonding may even be extended to phosphates and phosphonic acids after replacing the surface protons by $\mathrm{Zr}^{4+}$ or $\mathrm{Sn}^{4+}$. Attachment of a functional group to the surface bonding ligands including phosphates or phosphonic acids, allows using this large class of functionalized materials for a variety of applications. Because of the extraordinary properties of this compound, a great variety of potential and realized uses have been invoked. As a result, from 1964 to the present, more than 10,000 scientific papers have been published describing the chemistry and applications of this remarkable compound. This phenomenon continues as every year a few hundred new papers appear in the chemical literature.

In our Lab, both $\alpha$-TiP $[9,10]$ and its propylamine intercalation product, $\alpha$-Ti( $\left(\mathrm{HPO}_{4}\right)_{2} \cdot 2 \mathrm{C}_{3} \mathrm{H}_{7} \mathrm{NH}_{2} \cdot \mathrm{H}_{2} \mathrm{O}$ ( $\alpha$-TiPPr) [11-13], have been previously synthesized and characterized. On the other hand, the treatment of $\alpha$-TiPPr with europium(III) nitrate solutions, involving an ion-exchange process between propylammonium cations, $\mathrm{C}_{3} \mathrm{H}_{7} \mathrm{NH}_{3}{ }^{+}$, and hexahydrate europium(III) species, $\left[\mathrm{Eu}\left(\mathrm{H}_{2} \mathrm{O}\right)_{6}\right]^{3+}$, has led to a new luminescent material ( $\alpha$-EuTiPPr) [14].

Despite the large volume of information obtained in recent decades, the kinetic studies on the thermal decomposition processes of layered titanium phosphates are relatively scarce [15-18]. This contribution reports the kinetic features of thermo-oxidative decomposition processes of the three aforementioned 
materials: $\alpha$-TiP, $\alpha$-TiPPr, and $\alpha$-EuTiPPr.

\section{Experimental procedures}

All chemicals used were of reagent grade. MilliQ water was used throughout the experiments. $\alpha$ TiP was obtained by the method described by Alberti et al. [1], using $10 \mathrm{M} \mathrm{H}_{3} \mathrm{PO}_{4}$ and amorphous titanium phosphate $\left(\mathrm{PO}_{4} / \mathrm{Ti}=1.3\right)$ heated under reflux for $50 \mathrm{~h}$. Propylamine intercalation compound, $\alpha$ TiPPr, was obtained by placing $\alpha$-TiP in an atmosphere saturated with propylamine vapor during 6 days at room temperature [11]. $\alpha$-EuTiPPr was prepared by equilibrating $\alpha$-TiPPr with $0.1 \mathrm{M}$ europium nitrate $\mathrm{Eu}\left(\mathrm{NO}_{3}\right)_{3} \cdot 5 \mathrm{H}_{2} \mathrm{O}$ solution $\left(T=25.0 \pm 0.1^{\circ} \mathrm{C}, \mathrm{t}=72 \mathrm{~h}\right.$, solution $/$ solid ratio $\left.=20 \mathrm{~mL} / \mathrm{g}\right)[14]$.

The phosphorus and titanium contents of the solids were determined by inductively coupled plasma mass spectrometry (ICP-MS) analysis (Finnigan, Element model) after dissolving a weighed amount in $\mathrm{HF}(\mathrm{aq})$. Microanalytical data $(\mathrm{C}$ and $\mathrm{N}$ ) were determined by an Elementar Model Vario MACRO elemental analyser. Elemental analysis (wt\%) for $\alpha$-TiP: P 23.9, Ti 18.6 (calculated for Ti( $\left.\mathrm{HPO}_{4}\right)_{2} \cdot \mathrm{H}_{2} \mathrm{O}: \mathrm{P}$ 24.03, Ti 18.56), $\alpha$-TiPPr: P 16.7, Ti 12.8, C 18.8, N 7.3 (calculated for $\mathrm{Ti}\left(\mathrm{HPO}_{4}\right)_{2} \cdot 2 \mathrm{C}_{3} \mathrm{H}_{7} \mathrm{NH}_{2} \cdot \mathrm{H}_{2} \mathrm{O}: \mathrm{P}$ 16.47, Ti 12.73, C 19.16, N 7.45), and $\alpha$-EuTiPPr: P 13.7, Ti 10.8, Eu 24.0, C 2.5, N 0.9 (calculated for $\left.\left[\mathrm{Eu}\left(\mathrm{H}_{2} \mathrm{O}\right)_{6}\right]_{2 / 3} \mathrm{Ti}\left(\mathrm{PO}_{4}\right)_{2} \cdot\left[\left(\mathrm{H}_{2} \mathrm{O}\right)_{6}\right]_{1 / 3}: \mathrm{P} 14.85, \mathrm{Ti} 11.47, \mathrm{Eu} 24.28\right)$.

Powder diffraction studies. Room temperature X-ray powder diffraction (XPD) patterns were collected on an X'Pert PRO MPD X-ray diffractometer with PIXcel detector, operating in the BraggBrentano $(\theta / 2 \theta)$ geometry and using $\mathrm{CuK}_{\alpha}$ radiation $(\lambda=1.5418 \AA)$.

Electron microscopy studies. SEM images were obtained by using JEOL 6610VL scanning electron microscope operating at $20 \mathrm{kV}$ and equipped with an X-Max Silicon Drift Detector for EDX analysis.

Solid-state nuclear magnetic resonance studies. Room temperature SS-NMR spectra were collected on a Bruker AVANCE III 400 equipped with a 4-mm wide-bore MAS probe, operating at ${ }^{31} \mathrm{P}$ resonating frequency of $161.97 \mathrm{MHz}$ and ${ }^{13} \mathrm{C}$ resonating frequency of $100.64 \mathrm{MHz}$. Samples were packed in zirconia rotor with Kel-F tape. ${ }^{31} \mathrm{P}$ MAS NMR spectra were acquired at $8 \mathrm{kHz}$ spin rate. The relaxation delays were $20 \mathrm{~s}$ and number of scans of 100. All the spectra were referred to $\mathrm{NH}_{4} \mathrm{H}_{2} \mathrm{PO}_{4}(\delta=0.9 \mathrm{ppm})$ as external standard for chemical shift calibration. ${ }^{13} \mathrm{C}$ CPMAS NMR spectra were acquired at $5 \mathrm{kHz}$ spin rate. The relaxation delays for all spectra were $5 \mathrm{~s}$ and number of scans 100 . Chemical shift was externally referenced to the $43.5 \mathrm{ppm}$ resonance of glycine. 
Thermal analysis. A Mettler-Toledo TGA/SDTA851 ${ }^{\mathrm{e}}$ was used for the thermal analyses in a dynamic oxygen atmosphere $\left(50 \mathrm{~mL} \mathrm{~min}^{-1}\right)$ at several heating rates $\left(\beta=2.5,5,10,20,40 \mathrm{~K} \mathrm{~min}^{-1}\right)$. In all cases, ca. $15 \mathrm{mg}$ of powder sample was thermally treated, and blank runs were performed. A Pfeiffer Vacuum ThermoStar ${ }^{\mathrm{TM}}$ GSD301T mass spectrometer was used to determine the evacuated vapours. The masses 18 $\left(\mathrm{H}_{2} \mathrm{O}\right), 44\left(\mathrm{CO}_{2}\right)$ and $59\left(\mathrm{C}_{3} \mathrm{H}_{7} \mathrm{NH}_{2}\right)$ were tested by using a detector C-SEM, operating at $1200 \mathrm{~V}$, with a time constant of $1 \mathrm{~s}$.

Determination of kinetic parameters. The kinetics of many solid-state reactions involving a change of mass can be described by the basic equation

$$
\frac{\mathrm{d} \alpha}{\mathrm{d} t}=A \exp \left(-\frac{E}{R T}\right) f(\alpha)
$$

where $\alpha$ is the extent of conversion, $t$ is the time, $T$ is the temperature, $A$ is the Arrhenius factor, $E$ is the activation energy, $R$ is the universal gas constant and $f(\alpha)$ is the reaction model. Although the mechanisms in solid state reactions are usually very complex and tend to involve several steps, Eq (1) represents a simple kinetic model which can be used to describe an approximation of the kinetics of the process [19-21].

Many methods have been developed in order to estimate the kinetic parameters and nowadays, one can say that the most reliable results are provided by isoconversional methods. These methods are based on the isoconversional principle that states that the reaction rate depends only on the temperature for a given value of the extent of conversion. Several runs with different heating programmes, usually with constant heating rates $T=T_{0}+\beta_{i} t$, are carried out and then the values of the activation energy are computed from experimental data.

The differential method of Friedman comes from Eq. (1) by taking logarithms

$$
\ln \left(\left(\frac{\mathrm{d} \alpha}{\mathrm{d} t}\right)_{\alpha, i}\right)=\ln (A f(\alpha))-\frac{E_{\alpha}}{R T_{\alpha, i}}
$$

where $T_{\alpha, i}$ denotes the temperature at which $\alpha$ is reached for the $\mathrm{i}$-th heating program. Then, by plotting $\ln \left(\left(\frac{\mathrm{d} \alpha}{\mathrm{d} t}\right)_{\alpha, i}\right)$ against $1 / T_{\alpha, i}$, the value of $E_{\alpha}$ can be estimated. As is well-known, a drawback of this procedure is its sensitivity to noise, in particular, when it is applied to data coming from thermogravimetric analysis (TG).

In order to decrease the effects of noise, a modified procedure (MFR) was proposed by Huidobro et al. [22]. The underlying idea is, for a given value of $\alpha$, to consider not only the data corresponding to $\alpha$ 
but including data of surrounding points. So, five points $\alpha_{1}=\alpha-2 \Delta \alpha, \alpha_{2}=\alpha-\Delta \alpha, \alpha_{3}=\alpha, \alpha_{4}=$ $\alpha+\Delta \alpha, \alpha_{5}=\alpha+2 \Delta \alpha$, for $\mathrm{n}$ heating programmes, are considered and Eq. (2) leads to

$$
\ln \left(\frac{\mathrm{d} \alpha\left(t_{k, i}\right)}{\mathrm{d} t}\right)=\ln \left(A f\left(\alpha_{k}\right)\right)-\frac{E}{\mathrm{R} T_{k, i}}, k=1, \ldots, 5
$$

These five points are very close and assuming that variations of the activation energy over the interval $\left[\alpha_{1}, \alpha_{5}\right]$ are neglected, Eq. (3) involves five different straight lines with the same slope $m=-E / R$. Thus, we can find the slope by fitting to the experimental data for all these points simultaneously rather than only for $\alpha$. This method can be applied to a different number of points.

Integral isoconversional methods are based on an integral of Eq. (1)

$$
g(\alpha)=\int_{t_{0}}^{t_{\alpha}} \exp \left(-\frac{E}{R T}\right) d t
$$

where $g(\alpha)=\int_{0}^{\alpha}[1 /(A f(\alpha))] \mathrm{d} \alpha$. The integral on the right-hand side of Eq. (4) is known as temperature integral and does not have an analytical solution and, for this reason, several approximations have been proposed giving rise to different methods. Although some of them are very popular [23], they have been criticized because of the inconsistency of their formulation, particularly when the activation energy changes with the extent of conversion [24,25].

The non-linear advanced method proposed by Vyazovkin [24,26] is one of the most accurate procedures for kinetic analysis. For a small increment of conversion $\Delta \alpha$ and assuming that $A$ is constant over the interval $[\alpha-\Delta \alpha, \alpha]$, integration of Eq. (1) with respect to $t$ gives

$$
\int_{\alpha-\Delta \alpha}^{\alpha} \frac{1}{A f(\alpha)} \mathrm{d} \alpha=J\left(E_{\alpha}\right)
$$

where $J\left(E_{\alpha}\right)=\int_{t_{\alpha-\Delta \alpha}}^{t_{\alpha}} \exp \left(-E_{\alpha} / R T\right) d t$. Then, for a given value of $\alpha$ and several runs $i=1, \ldots n$, the $J_{\alpha, i}$ 's should be equal. To obtain $E_{\alpha}$ Vyazovkin proposed the minimization of the function

$$
\Phi\left(E_{\alpha}\right)=\sum_{i=1}^{n} \sum_{j \neq i}^{n} \frac{J_{i}\left(E_{\alpha}\right)}{J_{j}\left(E_{\alpha}\right)}
$$

Numerical integration has been used to evaluate $J\left(E_{\alpha}\right)$.

\section{Results and discussion}

XPD analysis shows that $\alpha$-TiP is highly crystalline (Fig. 1a) with the first characteristic peak at $2 \theta=$ $11.65^{\circ}\left(d_{002}=7.58 \AA\right)$ corresponding to its interlayer distance. In $\alpha$-TiPPr, the basal spacing increases up 
to $16.9 \AA$ (Fig. 1b) as a consequence of the propylamine intercalation as a bimolecular film [11] in which the terminal amino groups are protonated by the $\mathrm{POH}$ groups and the carbon chains are roughly inclined by $59^{\circ}$ to the titanium phosphate layers, showing a similar packing to that reported for $\gamma$-titanium phosphate intercalation compounds [27,28]. $\alpha$-EuTiPPr presents a structural order in the direction perpendicular to the plane of the sheet with a diffraction peak at $2 \theta=7.33^{\circ}$ corresponding to a $d$-spacing of $12.0 \AA$ (Fig. 1c). This new peak was attributed to the formation of an Eu-phase with the idealized formula $\left[\mathrm{Eu}\left(\mathrm{H}_{2} \mathrm{O}\right)_{6}\right]_{2 / 3} \mathrm{Ti}\left(\mathrm{PO}_{4}\right)_{2} \cdot\left[\left(\mathrm{H}_{2} \mathrm{O}\right)_{6}\right]_{1 / 3}$, where $\left[\mathrm{Eu}\left(\mathrm{H}_{2} \mathrm{O}\right)_{6}\right]^{3+}$ occupying $2 / 3$ of the pseudo-zeolitic cavities so as to counteract the negatively charged titanium phosphate layer, while the rest of the pseudozeolitic cavities (1/3 of the total) are supposed to be occupied by water molecules [14].

SEM images (Fig. 2) show that all three samples present a platelet-like pseudo-hexagonal morphologies typical of the layered metal phosphates [29], indicating that in this case both intercalation and ion-exchange processes preserve the sheets integrity of the $\alpha$-titanium phosphate.

The ${ }^{31}$ P MAS NMR spectrum of $\alpha$-TiP (Fig. 3a, Table 1) shows two partially resolved peaks that according to the crystal data, correspond to two inequivalent $\mathrm{HPO}_{4}$ groups in titanium phosphate layers [10]. After treatment with propylamine, the ${ }^{31}$ P MAS NMR spectrum became substantially different for $\alpha$ TiPPr. The former two signals transformed into a dozen peaks (Fig. 3b, Table 1), indicating a high disorder of the propylamine molecules in the interlayer space. The ${ }^{13} \mathrm{C}$ CPMAS NMR spectrum of $\alpha-$ TiPPr (Fig. 4a) displays three resonances at $c a .41 .3,21.8$ and $11.6 \mathrm{ppm}$, which correspond to three different carbon types $(\alpha, \beta$ and $\gamma)$ in the propylamine, indicating that the intercalated propylamine is protonated [30]. However, the titanium phosphate sample containing europium ( $\alpha$-EuTiPPr) does not present any relevant signal in the ${ }^{13} \mathrm{C}$ CPMAS NMR experiment (Fig. 4b). The carbon content in the sample is below the sensitivity of the NMR experiment used in the measurements of ${ }^{13} \mathrm{C}$. The ${ }^{31} \mathrm{P}$ MAS NMR spectrum of $\alpha$-EuTiPPr shows fairly broad peaks in the range between $0 \mathrm{ppm}$ and $-40 \mathrm{ppm}$ (Fig. 3c, Table 1) and provides very little information, probably as a result of two assistant effects: the disorder in the interlayered space occupied by one layer of cationic species and the local magnetic field in the environment of the europium(III) cations.

Figure 5 displays the TG-DTG curves for the three studied materials. The DTG curve of $\alpha$-TiP (Fig. 5a) shows two minima, the first corresponds to the loss of hydration water at $c a .495 \mathrm{~K}$ and the second is due to the elimination of condensation water at $795 \mathrm{~K}$, with a total mass loss of $14.5 \%$ (calculated for $\left.\operatorname{Ti}\left(\mathrm{HPO}_{4}\right)_{2} \cdot \mathrm{H}_{2} \mathrm{O}: 13.95 \%\right)$. The TG-DTG curves of $\alpha$-TiPPr (Fig. $5 \mathrm{~b}$ ) show a complex decomposition 
behavior from the beginning of the process up to obtaining the final titanium diphosphate phase $\left(\mathrm{TiP}_{2} \mathrm{O}_{7}\right)$ with a total mass loss of $39.5 \%$ (calculated: $40.96 \%$ ), and the probable formation of several $\alpha$ $\mathrm{Ti}\left(\mathrm{HPO}_{4}\right)_{2} \cdot \mathrm{xC}_{3} \mathrm{H}_{7} \mathrm{NH}_{2}(\mathrm{x}=2.0,1.7,1.3,1.0$, and 0.5$)$ intermediate phases [31]. The first DTG peak at 353 $\mathrm{K}$ is associated with the loss of the hydration water, while the signals in the $400-1000 \mathrm{~K}$ range are related to the loss of both propylamine and condensation water (see MS-data: $\mathrm{H}_{2} \mathrm{O}$ and $\mathrm{C}_{3} \mathrm{H}_{7} \mathrm{NH}_{2}$ signals, in Fig. 6a). Finally, the last peak (at $1173 \mathrm{~K}$ ) corresponds to the combustion of organic matter occluded in the compound (see $\mathrm{CO}_{2}$-signal, in Fig. 6a), as previously reported for other amine-metal phosphates [32].

The TG-DTG curves of $\alpha$-EuTiPPr (Fig. 5c) show that the material decomposes in several overlapping steps with water evacuation from room temperature up to $1000 \mathrm{~K}$ (see MS-data, in Fig. 6b). In addition to the loss of water, at 500-600 K, the loss of propylamine is also observed according to the elemental composition data (see Table 1 in Ref. [14] where the residual amounts of organic matter in $\alpha$ EuTiPPr are reported). Again, the combustion of small amounts of organic matter trapped on the collapsed solid is also observed at high temperatures ( $c$ a. $1200 \mathrm{~K})$.

The kinetic study for the thermo-oxidative decomposition of the three materials $(\alpha$-TiP, $\alpha$-TiPPr, and $\alpha$-EuTiPPr) was performed using thermogravimetric data obtained in air atmosphere at several constant heating rates $\left(\beta=2.5,5,10,20,40 \mathrm{~K} \mathrm{~min}^{-1}\right)$. The kinetic evaluation was carried out by using the modified method of Friedman (MFR) [22] and the advanced nonlinear method proposed by Vyazovkin (Vyaz) [24,26]. The apparent activation energy as a function of the extent of conversion was calculated considering an increment $\Delta \alpha=0.01$. In all cases, the $E$ values obtained by applying both the MFR and Vyaz methods are very close to each other.

For $\alpha$-TiP sample, Figure 7 shows two distinguished zones for the activation energy corresponding to the loss of water. The first zone, for the conversion range $0.15 \leq \alpha \leq 0.50$, is associated to the evacuation of hydration water with an average activation energy of $70 \mathrm{~kJ} \mathrm{~mol}^{-1}$. The second conversion range, $0.60 \leq \alpha \leq 0.90$, corresponds to the loss of condensation water and the activation energy is relatively higher, about $205 \mathrm{~kJ} \mathrm{~mol}^{-1}$. These results show a good agreement with the experimental TGDTG curves (Fig. 5a).

The $E-\alpha$ curves for the other two materials, $\alpha$-TiPPr in Figure $8 \mathrm{a}$ and $\alpha$-EuTiPPr in Figure $8 \mathrm{~b}$, have a more irregular shape due to the overlapping mass loss processes. For a better understanding of this behavior, we have plotted both the apparent activation energy and the mass spectrometry signals $(\mathrm{m} / \mathrm{z}, 18$ $\mathrm{H}_{2} \mathrm{O}, \mathrm{m} / z 44 \mathrm{CO}_{2}$, and $\mathrm{m} / z 59 \mathrm{C}_{3} \mathrm{H}_{7} \mathrm{NH}_{2}$ ) versus the extent of conversion for these two compounds. In the 
case of $\alpha$-TiPPr, Figure 8a, a part of the hydration water is lost for $\alpha<0.2$, and then, over the extent of conversion range $0.2 \leq \alpha \leq 0.5$, a part of the propylamine is lost and the value obtained for the apparent activation energy is ca. $95 \mathrm{~kJ} \mathrm{~mol}^{-1}$. The first loss of water takes place in two overlapping steps, which are difficult to distinguish by thermogravimetric analysis, and the intercalated propylamine is lost in several overlapping steps [31]. When $\alpha=0.65$ (see Fig. 8a), $E$ reaches a maximum value of $300 \mathrm{~kJ} \mathrm{~mol}^{-1}$ that can be associated with the loss of the remaining hydration water and propylamine. For $\alpha$ ranging approximately between 0.65 and 0.85 , the apparent activation energy is about $160 \mathrm{~kJ} \mathrm{~mol}^{-1}$ and attributed to the loss of the condensation water. These experimental results match with the theoretically calculated extent of conversion: $\alpha$ between 0.12 and 0.69 for the loss of hydration water and propylamine, and $\alpha=$ 0.88 for the loss of condensation water.

For $\alpha$-EuTiPPr, the $E-\alpha$ and $m / z-\alpha$ curves are shown in Figure 8 b. In the first stage, for $\alpha$ between $c a .0 .1$ and 0.4 , the apparent activation energy is practically constant $\left(c a .50 \mathrm{~kJ} \mathrm{~mol}^{-1}\right)$. It corresponds to the largest loss of the hydration water. In the second stage, for $\alpha$ between $c a$. 0.45 and 0.65 , the loss of hydration water is finished and the loss of propylamine is detected. Finally, when $\alpha>0.65$, the $m / z-\alpha$ curves show the loss of both condensation water and propylamine.

When a collection of values $y_{i}, i=1, \ldots, n$, is approximated by the values $y_{i}^{*}$, the correlation factor given by $R^{2}=1-\sum_{i=1}^{n}\left(y_{i}-y_{i}^{*}\right)^{2} / \sum_{i=1}^{n}\left(y_{i}-\bar{y}\right)^{2}$, where $\bar{y}=\sum_{i=1}^{n} y_{i} / n$, informs about the goodness of the approximation. In this study, the excellent agreement of both MFR and Vyaz methods with the experimental data, in the whole temperature range and for several heating rates, is illustrated by the values of the correlation factor $R^{2}$ summarized in Table 2 . As can be seen, in all cases $R^{2}$ is near 1 . Apart from that, Figure 9 shows the reconstructed conversion curves and the experimental ones obtained in the laboratory for the three compounds at a heating rate $\beta=10 \mathrm{~K} \mathrm{~min}^{-1}$.

\section{Conclusions}

We have shown that the chemical modifications of the parent $\alpha$-TiP compound could be successfully performed by taking advantage of its intercalation and ion-exchange properties. The morphology of the particles for the intercalated and ion-exchange forms ( $\alpha$-TiPPr, and $\alpha$-EuTiPPr) is apparently similar to the parent $\alpha$-TiP compound. However, solid-state NMR and thermal analysis were able to detect structural differences between these three compounds. In addition, the apparent activation energy was estimated for the thermo-oxidative decomposition stages observed in TG experiments for all the studied materials. An excellent agreement between the both applied MFR and Vyaz methods and the 
experimental data was obtained.

\section{Acknowledgements}

This work is supported by "Ministerio de Economía y Competitividad" (MAT2016-78155-C2-1-R, MAT2013-40950-R, MAT2011-27573-C04-02), “Gobierno del Principado de Asturias” (GRUPIN14060), and FEDER.

\section{References}

[1] Alberti G, Cardini-Galli P, Costantino U, Torracca E. Crystalline insoluble salts of polybasic metals. 1. Ion-exchange properties of crystalline titanium phosphate. J Inorg Nucl Chem. 1967;29:571-8. doi: $10.1016 / 0022-1902(67) 80063-0$

[2] Alberti G, Torracca E. Crystalline insoluble salts of polybasic metals. 2. Synthesis of crystalline zirconium or titanium phosphate by direct precipitation. J Inorg Nucl Chem. 1968;30:317-8. doi: $10.1016 / 0022-1902(68) 80096-X$

[3] Clearfield A, Stynes JA. The preparation of crystalline zirconium phosphate and some observations on its ion exchange behavior. J Inorg Nucl Chem. 1964;26:117-29. doi: 10.1016/0022-1902(64)802384

[4] Chernorukov NG, Moskvich EP, Zhuk MI. Crystallographic characteristics of phosphates and arsenates of tetravalent elements. Kristallograf. 1974;19:1084-5.

[5] Suárez M, García JR, Rodríguez J. Calorimetric determination of $\mathrm{H}^{+} / \mathrm{Na}^{+}$ion-exchange on $\alpha$-titanium phosphate. J Phys Chem. 1984;88:157-9. doi: 10.1021/j150645a035

[6] Suárez M, García JR, Rodríguez J. Thermodynamic treatment of $\mathrm{H}^{+} / \mathrm{Na}^{+}$ion-exchange on $\alpha$-titanium phosphate. J Phys Chem. 1984;88:159-62. doi: 10.1021/j150645a036

[7] García JR, Suárez M, Guarido CG, Rodríguez J. X-Ray diffraction spectrometry for the analysis of crystalline solid phases. Anal Chem. 1984;56:193-6. doi: 10.1021/ac00266a016

[8] Clearfield A, Díaz A. Zirconium phosphate nanoparticles and their extraordinary properties. In Tailored organic-inorganic materials (Brunet E, Colón JL, Clearfield A, Eds.). John Wiley \& Sons, Inc., Hoboken, New Jersey. 2014. Pp 1-44.

[9] Llavona R, Suárez M, García JR, Rodríguez J. Lamellar inorganic ion exchangers. Alkali metal ion exchange on $\alpha$ - and $\gamma$-titanium phosphate. Inorg Chem. 1989;28:2863-8. doi: 10.1021/ic00313a033 
[10] Salvadó MA, Pertierra P, García-Granda S, García JR, Rodríguez J, Fernández-Díaz MT. Neutron powder diffraction study of $\alpha-\mathrm{Ti}\left(\mathrm{HPO}_{4}\right)_{2} \cdot \mathrm{H}_{2} \mathrm{O}$ and $\alpha-\mathrm{Hf}\left(\mathrm{HPO}_{4}\right)_{2} \cdot \mathrm{H}_{2} \mathrm{O} ; \mathrm{H}$-atom positions. Acta Cryst B. 1996;52:896-8. doi: 10.1107/S0108768196006702

[11] Menéndez F, Espina, A, Trobajo C, Rodríguez J. Intercalation of $n$-alkylamines by lamellar materials of the $\alpha$-zirconium phosphate type. Mater Res Bull. 1990;25:1531-9. doi: 10.1016/00255408(90)90130-T

[12] Espina A, Jaimez E, Khainakov SA, Trobajo C, García JR, Rodríguez, J. Synthesis of new n-alkylamines intercalation compounds with $\alpha$-titanium phosphate. Process selectivity and structural and morphological characterization. Chem Mater. 1998;10:2490-6. doi: 10.1021/cm9802090

[13] Espina A, García JR, Guil JM, Jaimez E, Parra JB, Rodríguez J. Calorimetric study of amine adsorption on $\alpha$ - and $\gamma$-titanium phosphate. J Phys Chem. 1998;102:1713-6. doi: 10.1021/jp972410o

[14] García-Glez J, Trobajo C, Khainakov SA, Amghouz Z. $\alpha$-Titanium phosphate intercalated with propylamine: An alternative pathway for efficient europium(III) uptake into layered tetravalent metal phosphates. Arab J Chem. 2017;10:885-94. doi: 10.1016/j.arabjc.2016.07.013

[15] Vecchio S, Di Rocco R, Ferragina C, Materazzi S. Thermal and kinetic study of dehydration and decomposition processes for copper intercalated $\gamma$-zirconium and $\gamma$-titanium phosphates. Thermochim Acta 2005;435:181-7. doi: 10.1016/j.tca.2005.04.029

[16] Vecchio S, Di Rocco R, Ferragina C. Kinetic analysis of the oxidative decomposition in $\gamma$-zirconium and $\gamma$-titanium phosphate intercalation compounds. The case of 2,2'-bipyridyl and its copper complex formed in situ. Thermochim Acta 2007;467:1-10. doi: 10.1016/j.tca.2007.10.015

[17] García-Granda S, Khainakov SA, Espina A, García JR, Castro GR, Rocha J, Mafra L. Revisiting the thermal decomposition of layered $\gamma$-titanium phosphate and structural elucidation of its intermediate phases. Inorg Chem. 2010;49:2630-8. doi: 10.1021/ic901254j

[18] García-Glez J, Amghouz Z, Khainakov SA, Espina A, Alfonso BF, Trobajo C. Ammoniumexchanged phase of $\gamma$-titanium phosphate. Hydrothermal synthesis, crystal structure, and thermal behavior. J Therm Anal Calorim. 2014;118:783-91. doi: 10.1007/s10973-014-3923-z

[19] Vyazovkin S, Burnham AK, Criado JM, Pérez-Maqueda LA, Popescu C, Sbirrazzuoli N. ICTAC Kinetic Committee recommendations for performing kinetic computations on thermal analysis data, Thermochim Acta. 2011;520:1-19. doi: 10.1016/j.tca.2011.03.034

[20] Simon P, Thomas PS, Okuliar J, Ray AS. An incremental integral isoconversional method. 
Determination of activation parameters. J Therm Anal Calorim. 2003;72: 867-74. doi: 10.1023_B JTAN.0000027811.80036.6c

[21] Sbirrazzuoli N, Vincent L, Mija A, Guigo N. Integral, differential and advanced isoconversional methods. Complex mechanisms and isothermal predicted conversion-time curves. Chemometr Intell Lab. 2009;96:219-26. doi: 10.1016/j.chemolab.2009.02.002

[22] Huidobro JA, Iglesias I, Alfonso BF, Espina A, Trobajo C, García JR. Reducing the effects of noise in the calculation of activation energy by the Friedman method. Chemometr Intell Lab. 2016;151:146-52. doi: 10.1016/j.chemolab.2015.12.012

[23] Ma Z, Chen D, Gu J, Bao B, Zhang Q. Determination of pyrolysis characteristics and kinetics of palm kernel shell using TGA-FTIR and model-free integral methods. Energ Convers Manage. 2015;89:251-9. doi: 10.1016/j.enconman.2014.09.074

[24] Vyazovkin S. Modification of the integral isoconversional method to account for variation in the activation energy, $\mathrm{J}$ Comput Chem. 2001;22:178-83. doi: 10.1002/1096987X(20010130)22:2<178::AID-JCC5>3.0.CO;2-\#

[25] Simon P, Thomas P, Dubaj T, Cibulkova Z, Peller A, Veverka M. The mathematical incorrectness of the integral isoconversional methods in case of variable activation energy and the consequences. J Therm Anal Calorim. 2014;115:853-9. doi: 10.1007/s10973-013-3459-7

[26] Vyazovkin S. Evaluation of activation energy of thermally stimulated solid-state reactions under arbitrary variation of temperature. J Comput Chem. 1997;18: 393-402. doi: 10.1002/(SICI)1096987X(199702)18:3<393::AID-JCC9>3.0.CO;2-P

[27] Mafra L, Paz FAA, Rocha J, Espina A, Khainakov SA, García JR, Fernández C. Structural characterization of layered $\gamma$-titanium phosphate $\left(\mathrm{C}_{6} \mathrm{H}_{13} \mathrm{NH}_{3}\right)\left[\mathrm{Ti}\left(\mathrm{HPO}_{4}\right)\left(\mathrm{PO}_{4}\right)\right] \cdot \mathrm{H}_{2} \mathrm{O}$. Chem Mater. 2005;17:6287-94. doi: $10.1021 / \mathrm{cm} 051447 \mathrm{f}$

[28] Mafra L, Rocha J, Fernández C, Castro GR, García-Granda S, Espina A, Khainakov SA, García JR. Characterization of layered $\gamma$-titanium phosphate $\left(\mathrm{C}_{2} \mathrm{H}_{5} \mathrm{NH}_{3}\right)\left[\mathrm{Ti}\left(\mathrm{H}_{1.5} \mathrm{PO}_{4}\right)\left(\mathrm{PO}_{4}\right)\right]_{2} \cdot \mathrm{H}_{2} \mathrm{O}$ intercalate: A combined NMR, synchrotron XRD, and DFT calculations study. Chem Mater. 2008;20:3944-53. doi: $10.1021 / \mathrm{cm} 800165 \mathrm{p}$

[29] Manickam M, Minato K, Takata M. Synthesis and electrochemical properties of $\mathrm{TiNb}\left(\mathrm{PO}_{4}\right)_{3}$ cathode materials for lithium secondary batteries. J Electroanal Chem. 2004;562:1-7. doi: 10.1016/j.jelechem.2003.08.005 
[30] MacLachlan DJ, Morgan KR. Solid-state NMR-studies of the structure of amine-intercalated $\alpha$ zirconium phosphate. Reaction of $\alpha$-zirconium phosphate with excess amine. J Phys Chem. 1990;19:7656-61. doi: 10.1021/j100382a062

[31] Espina A, Jaimez E, Suárez M, García JR, Rodríguez J. Thermal behavior of $\alpha$-titanium phosphate/nalkylamine intercalation compounds. Thermochim Acta 1992;210:263-72. doi: 10.1016/00406031(92)80296-9

[32] Fernández L, Espina A, Khainakov SA, Amghouz Z, García JR, García-Granda S. Novel ethylenediamine-gallium phosphate containing 6-fold coordinated gallium atoms with unusual four equatorial Ga-N bonds. J Solid State Chem. 2014;215:143-51. doi: 10.1016/j.jssc.2014.03.024 
Table 1. ${ }^{31} \mathrm{P}$ MAS NMR chemical shift values of the peaks observed in the spectra shown in Fig. 3

\begin{tabular}{ccc}
\hline $\boldsymbol{\alpha}$-TiP & $\boldsymbol{\alpha}$-TiPPr & $\boldsymbol{\alpha}$-EuTiPPr \\
\hline-18.4 & 1.5 & -11.4 \\
-18.7 & -12.4 & -15.0 \\
& -14.3 & -19.6 \\
& -14.8 & -23.6 \\
& -15.2 & \\
& -16.9 & \\
& -17.5 & \\
& -18.4 & \\
& -19.7 & \\
& -20.9 & \\
\hline
\end{tabular}

Table 2. Correlation factor in the fitting of the conversion obtained for the MFR and Vyaz methods, as a function of the heating rate $\left(\beta\right.$, in $\left.\mathrm{K} \mathrm{min}^{-1}\right)$

\begin{tabular}{lllllll}
\hline Sample & Method & $\boldsymbol{\beta}=\mathbf{2 . 5}$ & $\boldsymbol{\beta}=\mathbf{5}$ & $\boldsymbol{\beta}=\mathbf{1 0}$ & $\boldsymbol{\beta}=\mathbf{2 0}$ & $\boldsymbol{\beta}=\mathbf{4 0}$ \\
\hline \multirow{2}{*}{$\boldsymbol{\alpha}$-TiP } & MFR & 0.98564 & 0.95813 & 0.96282 & 0.96941 & 0.99771 \\
& Vyaz & 0.99251 & 0.96500 & 0.96589 & 0.96760 & 0.99475 \\
\hline \multirow{2}{*}{$\boldsymbol{\alpha - T i P P r}$} & MFR & 0.99897 & 0.99886 & 0.99930 & 0.99909 & -- \\
& Vyaz & 0.99820 & 0.99886 & 0.99924 & 0.99879 & --- \\
\hline \multirow{2}{*}{$\boldsymbol{\alpha - E u T i P P r}$} & MFR & 0.99833 & 0.97167 & 0.99662 & 0.99935 & --- \\
& Vyaz & 0.99694 & 0.96757 & 0.99518 & 0.99904 & --- \\
\hline
\end{tabular}




\section{FIGURE CAPTIONS}

Fig. 1 XPD patterns for $\alpha$-TiP (a), $\alpha$-TiPPr (b) and $\alpha$-EuTiPPr (c).

Fig. 2 SEM images for $\alpha-\operatorname{TiP}(\mathrm{a}), \alpha-\operatorname{TiPPr}(\mathrm{b})$ and $\alpha$-EuTiPPr (c).

Fig. $3{ }^{31}$ P MAS NMR spectra for $\alpha$-TiP (a), $\alpha$-TiPPr (b) and $\alpha$-EuTiPPr (c). These spectra show the number of observed peaks in each sample (a: 2 peaks, b: 11 peaks, c: 4 peaks) and the chemical shift for each peak is illustrated in Table 1.

Fig. $4{ }^{13} \mathrm{C}$ CPMAS NMR spectra for $\alpha$-TiPPr (a) and $\alpha$-EuTiPPr (b). Spectrum (a) shows 3 peaks and spectrum (b) no relevant peak is observed.

Fig. 5 TG (-) and DTG (-) curves for $\alpha$-TiP (a), $\alpha$-TiPPr (b) and $\alpha$-EuTiPPr (c) obtained at $10 \mathrm{~K} \mathrm{~min}^{-1}$ heating rate in $\mathrm{O}_{2}$-atmosphere.

Fig. 6 MS-signals of evacuated vapours on the TG-experiment $\left[m / z, 18\right.$ for $\mathrm{H}_{2} \mathrm{O}, \mathrm{m} / \mathrm{z} 44$ for $\mathrm{CO}_{2}$, and $\mathrm{m} / \mathrm{z}$ 59 for $\left.\mathrm{C}_{3} \mathrm{H}_{7} \mathrm{NH}_{2}\right]$ for $\alpha-\operatorname{TiPPr}$ (a) and $\alpha-\operatorname{EuTiPPr}(\mathrm{b})$.

Fig. 7 Dependence of the apparent activation energy on the extent of conversion for $\alpha$-TiP.

Fig. 8 Apparent activation energy and MS-signals of evacuated vapours $\left[\mathrm{m} / z, 18\right.$ for $\mathrm{H}_{2} \mathrm{O}, m / z 44$ for $\mathrm{CO}_{2}$, and $m / z, 59$ for $\mathrm{C}_{3} \mathrm{H}_{7} \mathrm{NH}_{2}$ ] versus extent of conversion for $\alpha$-TiPPr (a) and $\alpha$-EuTiPPr (b).

Fig. 9 Experimental and reconstructed $\alpha-T$ curves at $10 \mathrm{~K} \mathrm{~min}^{-1}$ heating rate for $\alpha$-TiP (a), $\alpha$-TiPPr (b) and $\alpha-\operatorname{EuTiPPr}(\mathrm{c})$. 


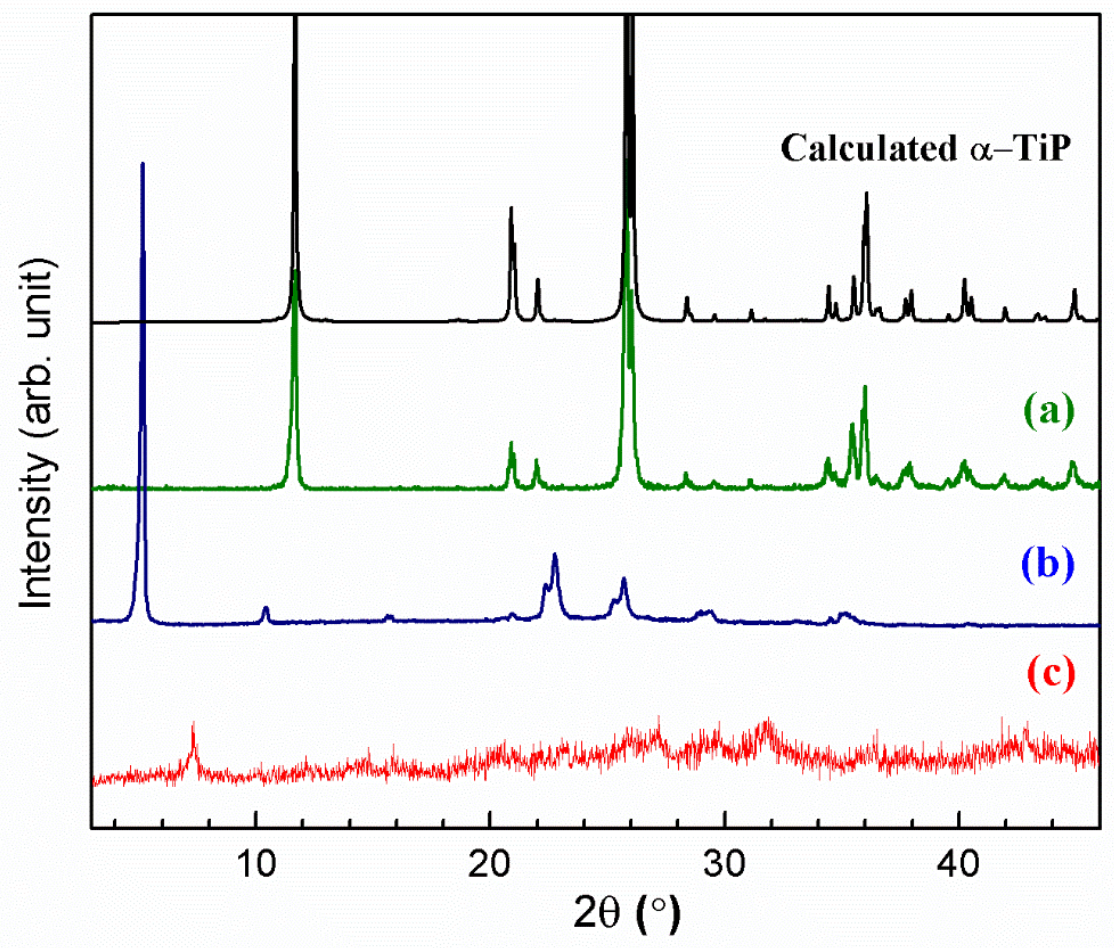

Figure 1 

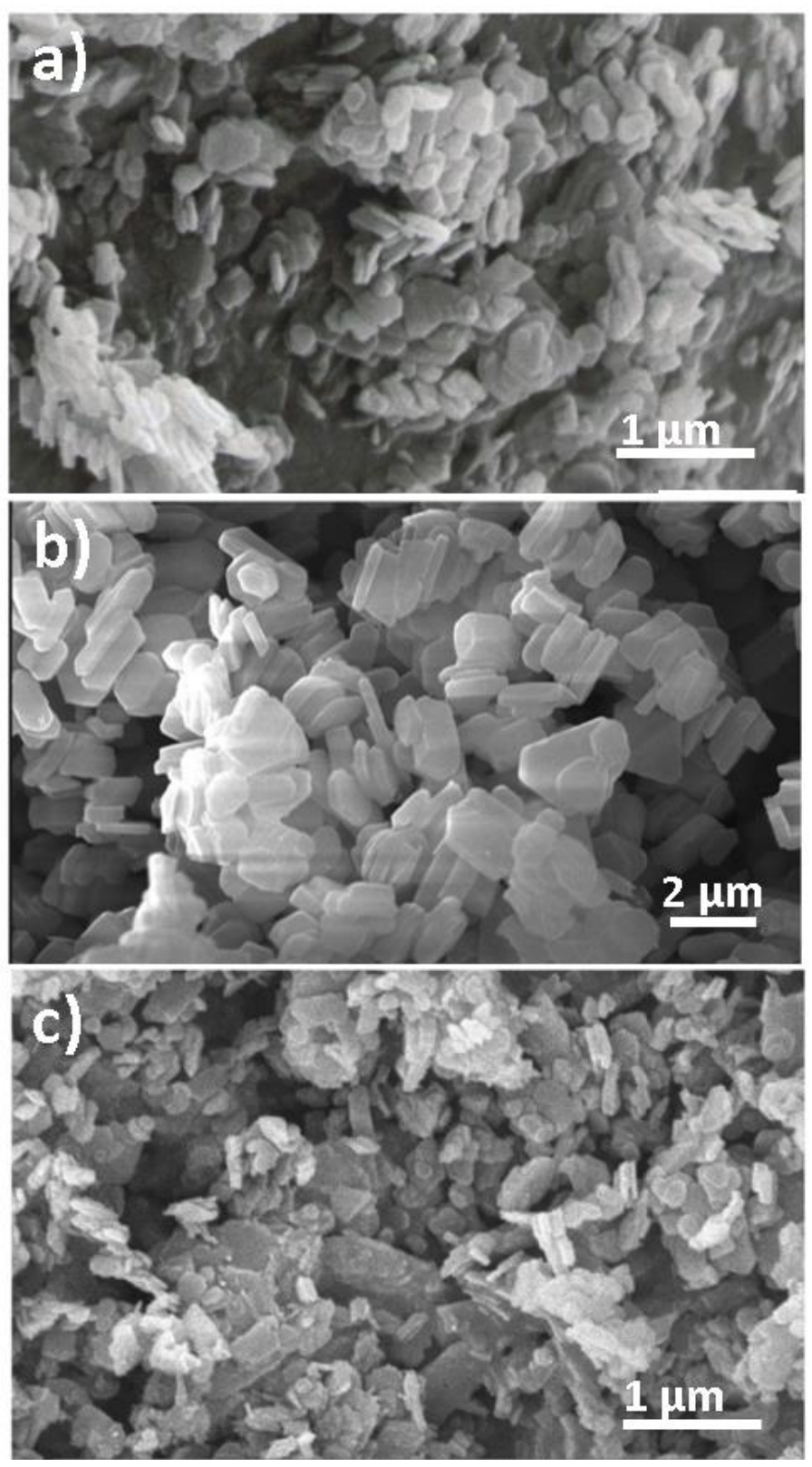

Figure 2 


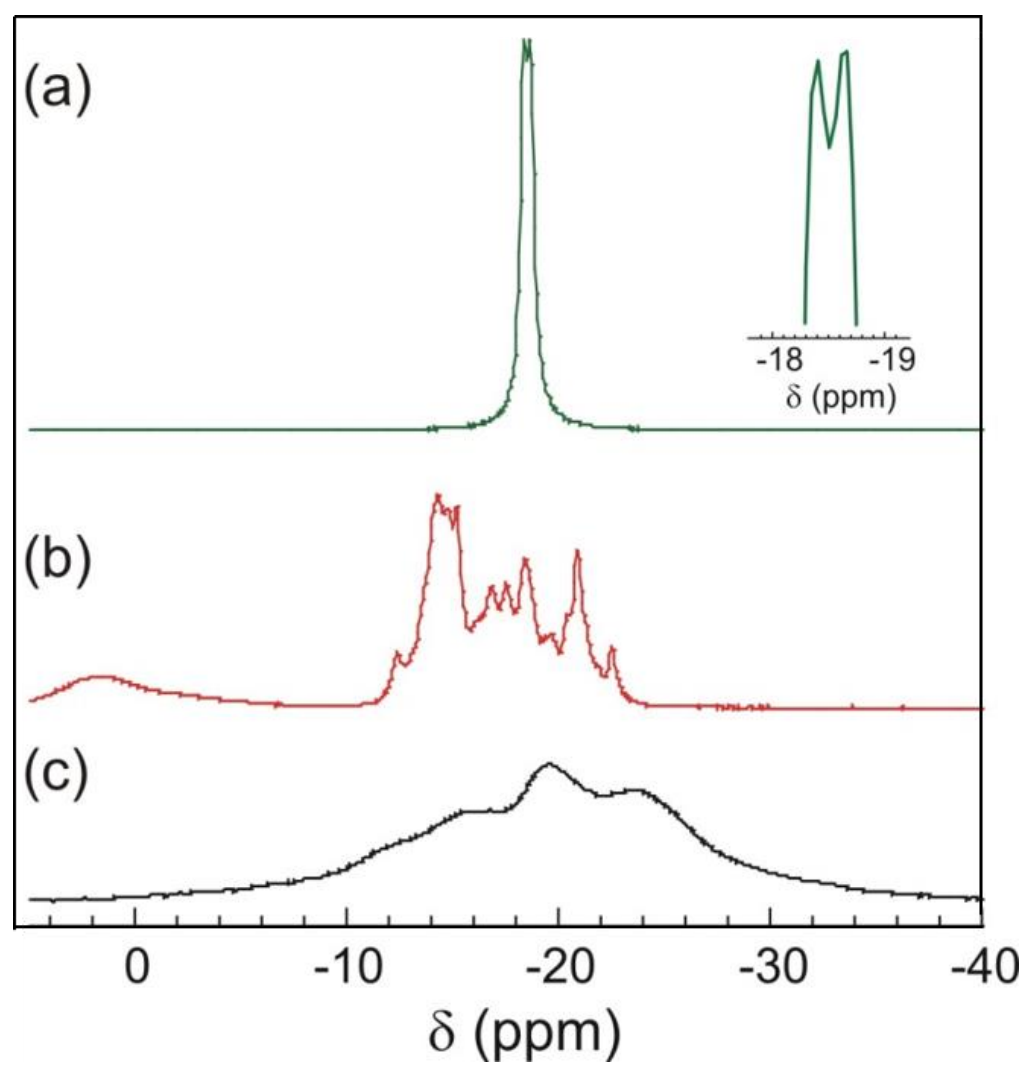

Figure 3

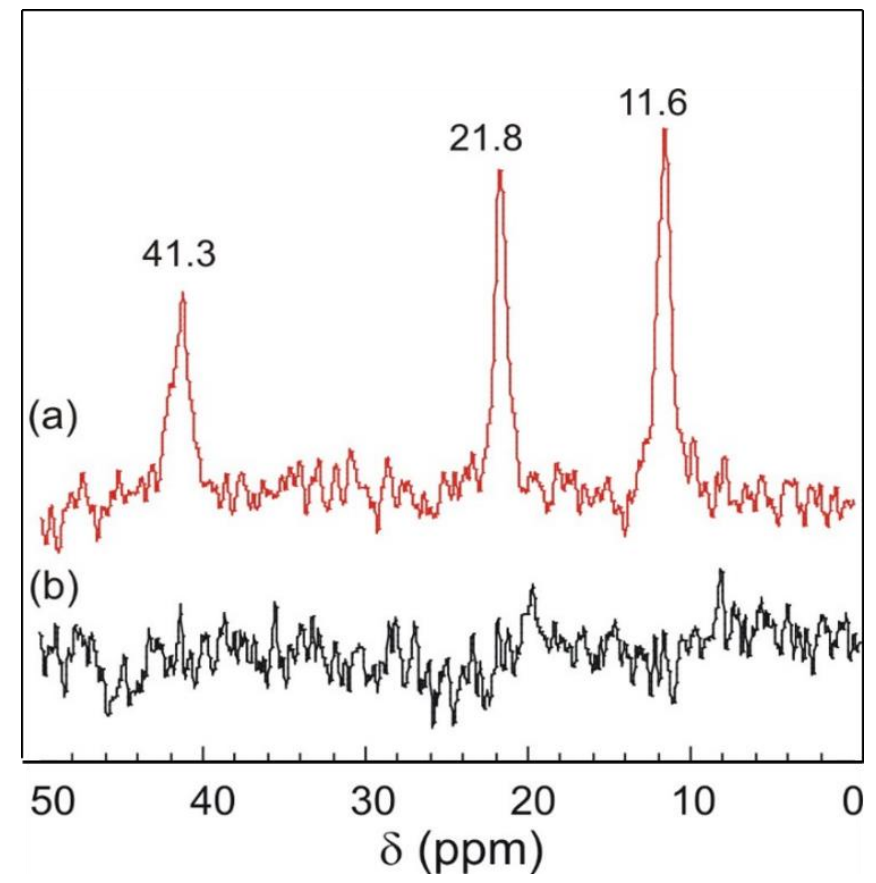

Figure 4 


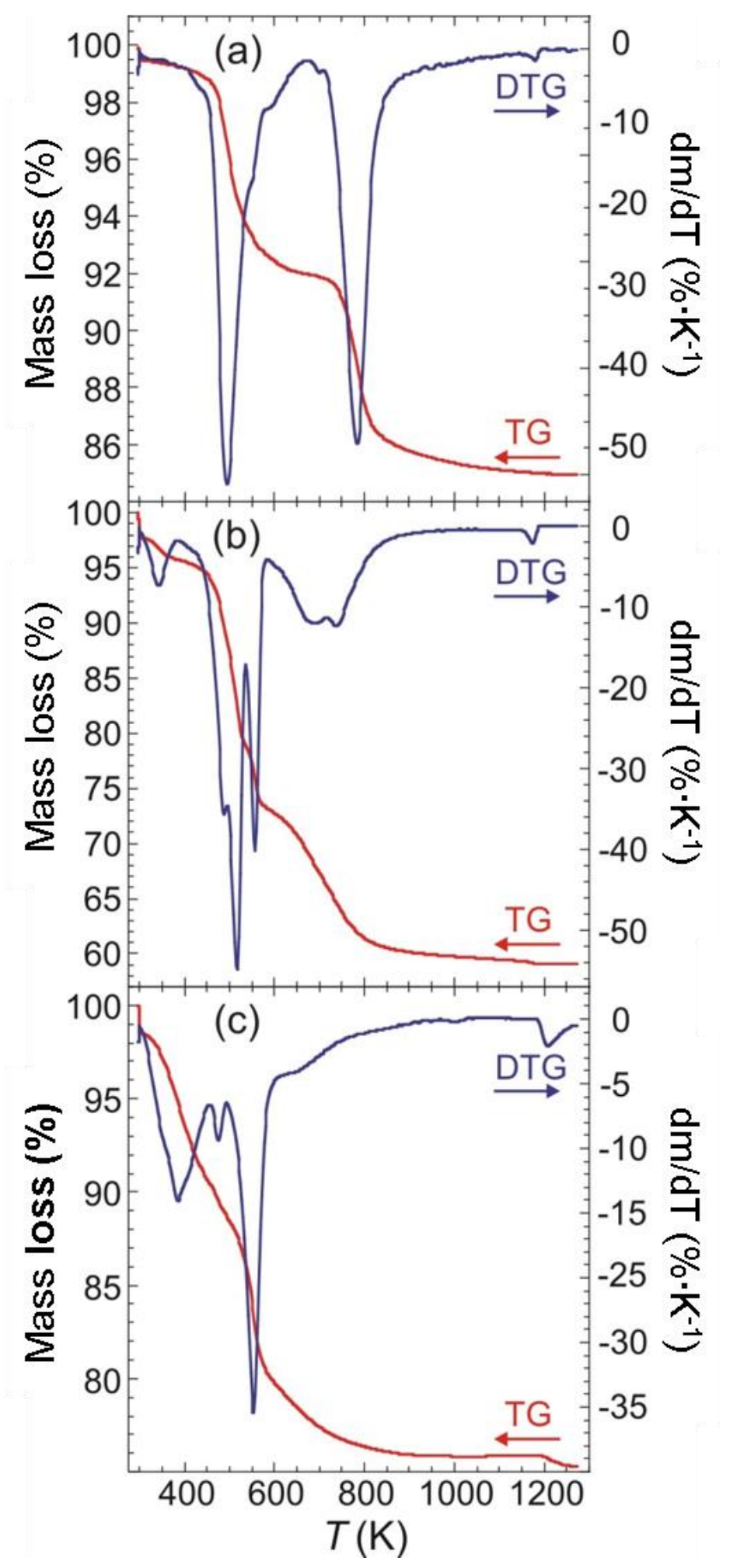

Figure 5 


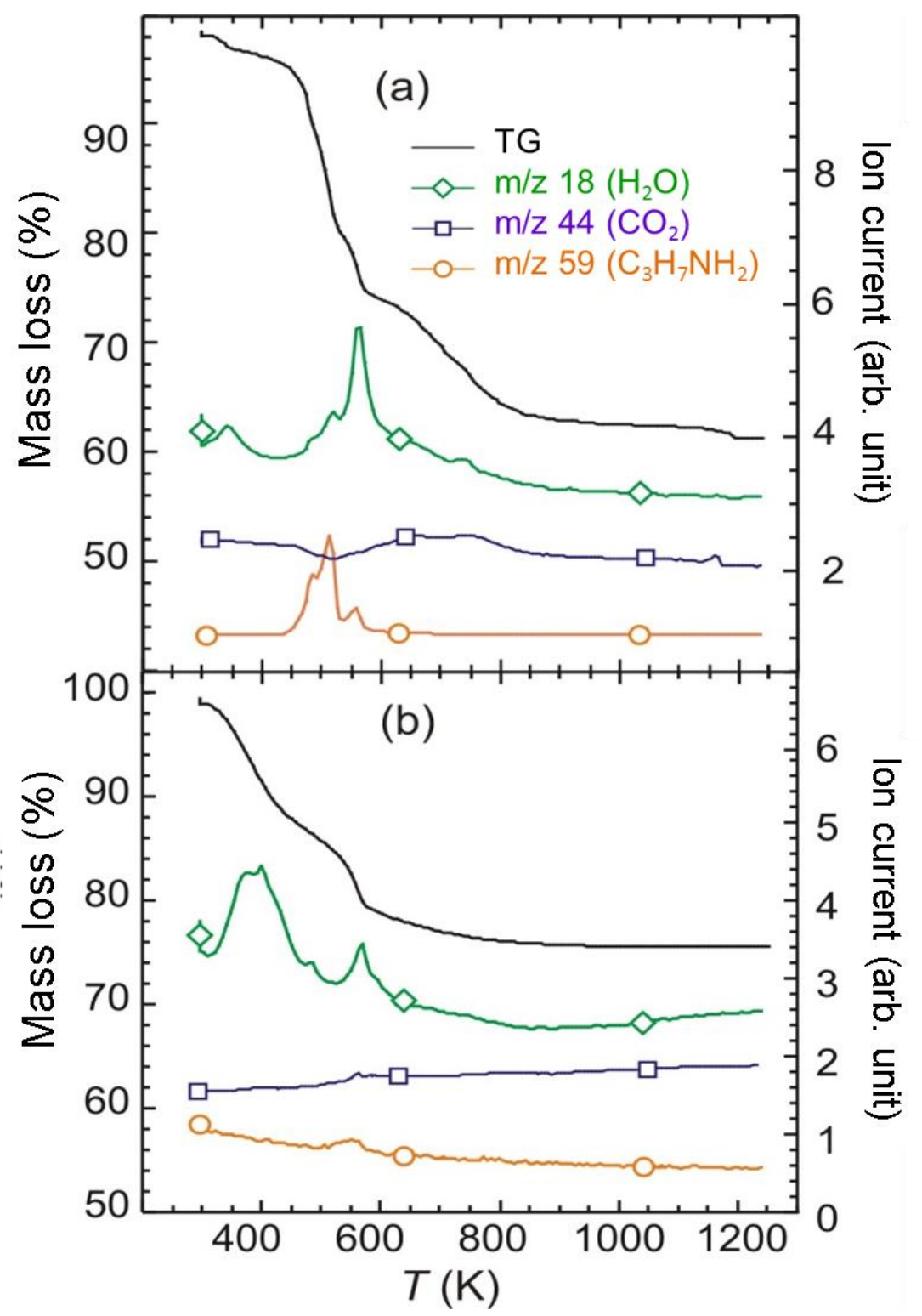

Figure 6 


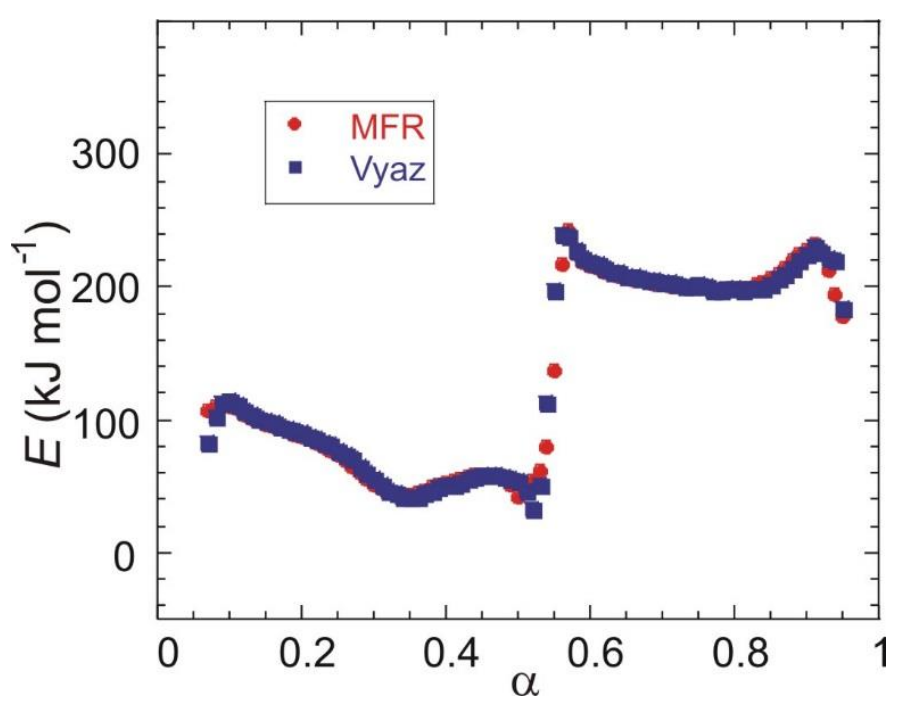

Figure 7

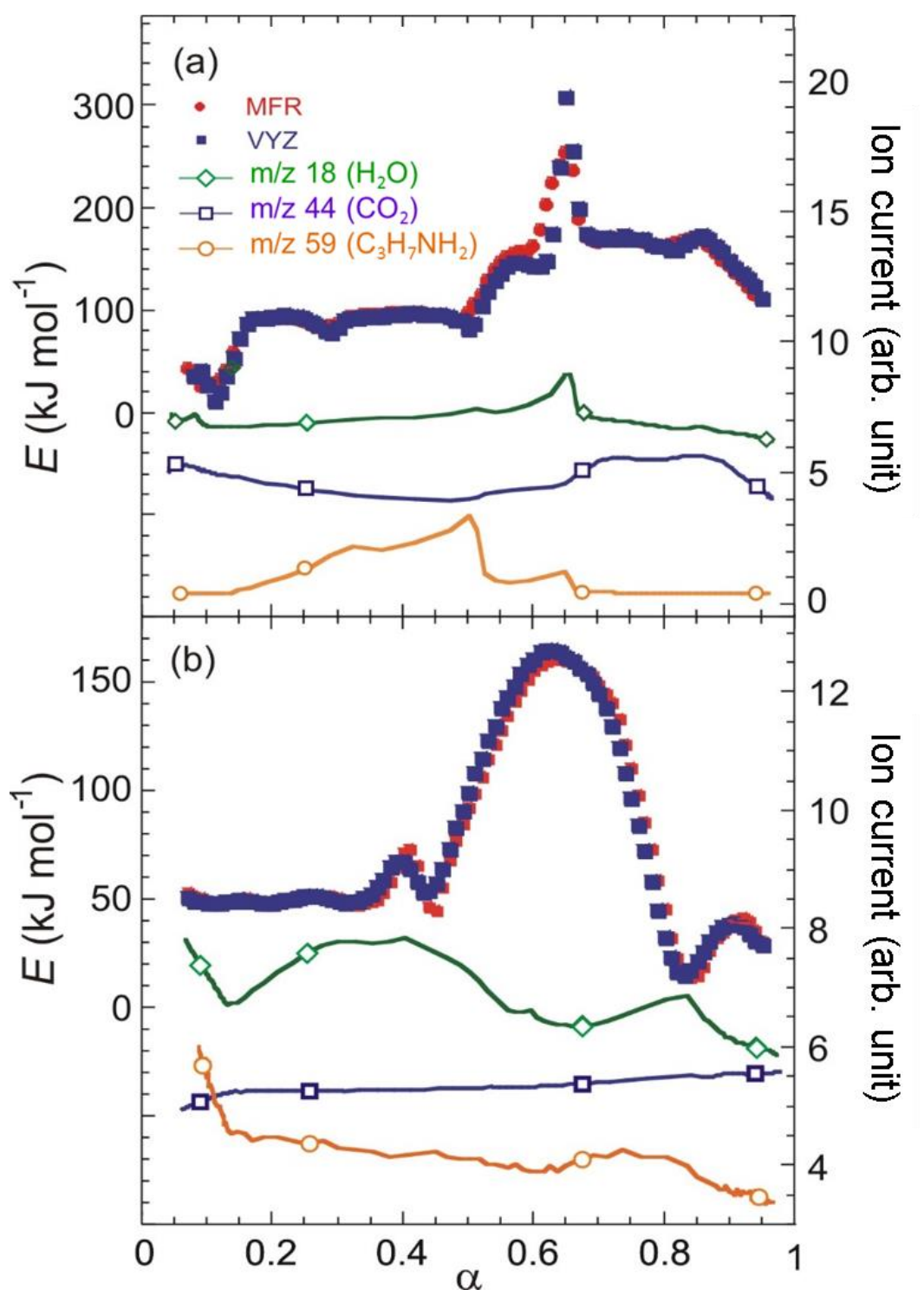

Figure 8 

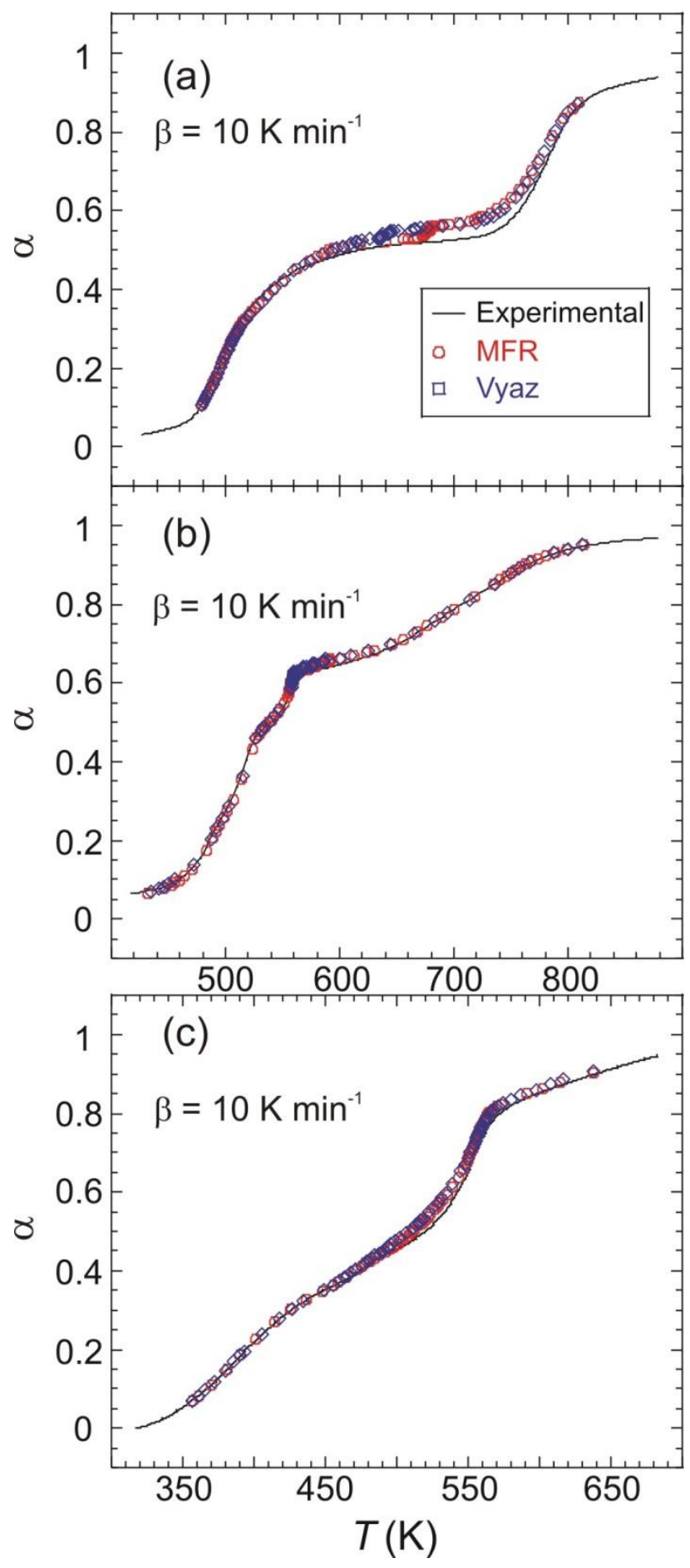

Figure 9 